\title{
Kidney Anastomotic Leakage
}

National Cancer Institute

\section{Source}

National Cancer Institute. Kidney Anastomotic Leakage. NCI Thesaurus. Code C78406.

Leakage of urine due to breakdown of a kidney anastomosis. 